\section{POLITICA Y TERRITORIALIDAD EN TRES CIUDADES ARGENTINAS}

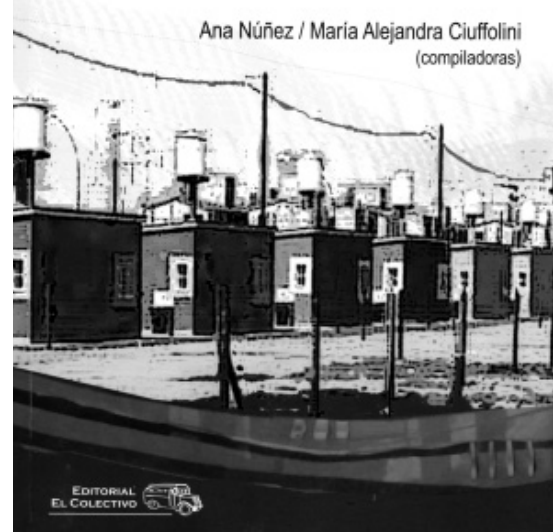

Políticas y territorialidad en tres ciudades argentinas. Ana NÚÑEZ y María Alejandra CIUFFOLINI (compiladoras). Editorial el Colectivo, 2011. Buenos Aires.

\section{Por Lorena C. Sánchez}

Arquitecta (FAU-UNNE); Magíster en Políticas Sociales (FHyCS-UNaM), Directora General de Ordenamiento Territorial de la Municipalidad de la Ciudad de Corrientes. Docente de Sociología General en Humanidades y Ciencias Económicas de la UNNE e integrante de la Unidad Ejecutora Provincial Chaco del Programa PROMEBA II como Consultora del Área Urbana en el período 2008/2010.

La Argentina de la última década ha sido objeto de distintas políticas públicas de viviendas que en un marco de apertura democrática apelan a la participación, evocan derechos sociales, habilitan inversiones y rediseñan modos para operar.

En este contexto, el libro Políticas y territorialidad en tres ciudades argentinas presenta siete artículos y se propone como un disparador para pensar la relación ciudad-sociedadestado centralmente desde tres puntos de análisis:

- $\quad$ luchas sociales y políticas públicas;

- trayectorias de políticas habitacionales e intervención estatal y

- $\quad$ sector inmobiliario y desarrolladores urbanos.

Estos artículos se encuentran entrelazados por una concepción común e intrínseca: la presentación del territorio como un lugar que refleja y habilita múltiples significantes de relaciones sociales. Contenido/continente, instituido/instituyente son dicotomías que propician la comprensión de variadas dinámicas de la acción social en el espacio "entendido como algo estrictamente político".

El conjunto de producciones realizadas por un equipo de diversas vertientes disciplinares, docentes e investigadores de universidades argentinas ofrece, además de rigurosidad 
científica y claridad narrativa, una visión crítica de temas relevantes, como legitimidad, intervención estatal y especulación inmobiliaria, implicados en la discusión/debate sobre vivienda, entendida en el concepto amplio de habitar.

En el primero de ellos, "Control del espacio y los recursos sociales: lógicas, relaciones y resistencias en la constitución de lo urbano", María Alejandra Ciuffolini plantea reflexionar sobre el espacio "como el resultado de un conjunto de dispositivos y de disposiciones sociales que a partir de la concurrencia interdependiente de las relaciones de fuerza desplegadas en torno al control y la posesión de los recursos sociales, configuran identidades y campos de comportamiento posibles". La autora advierte en su análisis que esas relaciones se organizan desde determinadas lógicas: la política-institucional, la económica-social y la dinámica de la resistencia, que son presentadas para pensar la fase actual del capital y su relación con el territorio.

En "Las miradas del olvido... como tragedia" y "Las moradas del olvido... como farsa", ANA NÚÑEZ, con una mirada retrospectiva, recompone y organiza "un proceso que atraviesa distintos momentos de la lucha de clases". En el primero de ellos la autora plantea como hipótesis que la política urbana debe ser entendida como "una forma de lucha social, que tiene su expresión en la lucha teórica, económica y política". Parte con una pregunta clave: “¿qué relaciones sociales se ocultan, se construyen y destruyen, detrás de la materialidad de los objetos, entendiendo por relación social la relación entre individuos, entre personas, mediadas por cosas a través de acciones, históricamente construidas y determinadas (Marín, 2009; Marx, 1965)". Su análisis, centrado en Mar del Plata, periodiza momentos que facilitan la comprensión de un proceso que devela contradicciones y anuncia la emergencia de formas socioterritoriales de apropiación del habitar.

En el segundo momento de análisis pone en crisis la legalidad dominante desatada por la génesis urbana como una ilegalidad fundante. "Porque el urbanismo oculta una estrategia de clase, e implica un doble fetichismo: a) el de la satisfacción, sobre la falsa hipótesis que es posible conocer y clasificar las necesidades y proporcionarles un objeto; y b) el del espacio, no logrando resolver el conflicto entre el uso y el intercambio, incluso cuando oprime al uso y al usuario".

La autora insta a reconocer y estudiar la práctica urbana, dado que "es un campo ciego, por el dominio y el sometimiento a su orden del proceso de urbanización”.

"Gestionar, concertar o decretar la provisión de viviendas en Córdoba. Análisis de los actores en el gobierno de lo habitacional”, de Gerardo Avalle y Gonzalo Ibáñez Mes- 
TRES, examina las políticas habitacionales de los tres últimos gobiernos provinciales de Córdoba, enfatizando en la dinámica de su construcción, modos, actores e impacto sobre destinatarios. Desde la prensa y el discurso de los beneficiarios "se procede a construir una narrativa que dé cuenta de los diferentes sentidos que se expresan a partir de la textualidad generada". Concertación-emergencia y escasez-megaplan y desarticulación presentan el núcleo de las tres fases temporales estudiadas "en la concepción de los agentes de gobierno en la forma de abordar la politica habitacional”. En ellas se presenta y configura "la posición que los sectores populares, pobres y de alta vulnerabilidad (beneficiarios de estas medidas) tenían dentro del proyecto político gobernante y el espacio que ocupaban en la esfera pública".

En "Mi casa, la emergencia; mi vida en emergencia. El escenario del programa Mi casa, Mi vida”, CANDELA DE LA VEGA y Juliana HeRnÁNDEZ resaltan "la retórica de la emergencia que envuelve y justifica el programa opera como un desvio de atención que, materializándose en un diseño y en acciones concretas, evade las problemáticas estructurales de estos sectores poblacionales y proporciona una base de legitimación para la producción y reproducción de relaciones de exclusión social”. Avanzan en el planteo del caso reconociendo que "la solución focalizada se encaró desde el lado de la asistencia y no como una medida inclusiva”.

“Lugares en emergencia o espacios emergentes? Contra-dicciones del territorio de La Tablada de la ciudad de Santa Fe luego de las inundaciones del año 2003”, de FERNÁN CROVELla, es un trabajo que explora "los modos que adoptan distintas fracciones sociales como respuesta a las necesidades que padecen, buscando avanzar en la comprensión de las determinaciones espaciales en la conformación de las relaciones y en la lucha por las condiciones de existencia", tomando como tema el suceso conocido como relocalización del barrio La Tablada, después de las inundaciones de 2003.

Conceptos como "prácticas espaciales - representaciones espaciales y momentos de representación” de LEFEBVRE (1974) y la idea de catástrofe hídrica "entendida como un constructo 'percibido y operacionalizado por una parte de la sociedad', de Roze (2003: 16), orientan esta investigación para reflexionar sobre cómo operan los dispositivos normalizadores estatales "en las representaciones del espacio", fundando los procesos expropiatorios de la territorialidad social "elementos para dilucidar las distintas formas en que el orden social consolida las relaciones de dominación vigentes”.

“Ciudades made in Manhattan”, de Mercedes Ferrero y Fernando Job. Analizan en la ciudad de Córdoba la construcción y los grandes negocios inmobiliarios, movilizados por 
el capital, que derivan del modelo agroexportador sojero, generando urbanizaciones de primera clase (barrios cerrados, countries, complejos de primera línea), ubicados en zonas céntricas o en las afueras en zonas exclusivas. Urbanizaciones que van de la mano de una "reconfiguración de los modos de establecimiento-imposición de lógicas de 'seguridad urbana y ciudadana' (...) que asegure las libertades cotidianas", que se vuelven argumentos de planificación y dinámicas policiales.

En paralelo este trabajo estudia el modo en que se instrumenta la política pública de erradicación de villas con el "Programa nuevos barrios: mi casa, mi vida", entendiéndolo como parte del sistema que compone el "modelo urbanístico-securitario cordobés". En este trabajo, los autores combinan el análisis y la relación de discursos, formas espaciales y lógicas estatales para pensar en términos de sociedad de control.

Se interpela al lector a pensar y pensarse en un conjunto de situaciones reconocibles que ameritan ser discutidas. Lectura necesaria para quienes abordan el tema del habitar sin hacerse sensibles a todas sus aristas. Las perspectivas del planificador, del usuario, del funcionario, del inversor son presentadas y recorridas como posiciones en tensión permanente, con una visión que deja fuera la posibilidad de entender las intervenciones urbanas, los reordenamientos o relocalizaciones, sin resignificar los procesos de apropiación o expropiación de la territorialidad social más o menos visibles. 